\title{
WPS 3293
}

\section{On the Conservation of Distance in International Trade}

\author{
Matias Berthelon \\ University of Maryland and \\ Pontificia Universidad Católica de Valparaíso \\ Caroline Freund \\ World Bank
}

\begin{abstract}
The volume of world trade has grown more than twice as fast as real world income since 1980. Surprisingly, the effect of distance on trade has increased during this period. It could be that countries are trading greater volumes of goods that are highly sensitive to distance. An alternative explanation is that distance has become more import for a significant share of goods. Using highly disaggregated bilateral trade data, we find that adjustment in the composition of trade has not influenced the way in which distance affects trade. In contrast, for about 25 percent of industries, distance has become more important. This implies that the increased distance sensitivity of trade is a result of a change in relative trade costs that affects many industries, as opposed to a shift to more distance-sensitive products. We also find that homogeneous products are twice as likely to have become more distance sensitive as compared with differentiated goods. This is consistent with the hypothesis that falling search costs, resulting from improvements in transport and communications, are relatively more important for differentiated goods. The results offer no evidence of the "death of distance," rather they suggest that distancerelated relative trade costs have remained unchanged or shifted in favor of proximate markets.
\end{abstract}

\section{World Bank Policy Research Working Paper 3293, May 2004}

The Policy Research Working Paper Series disseminates the findings of work in progress to encourage the exchange of ideas about development issues. An objective of the series is to get the findings out quickly, even if the presentations are less than fully polished. The papers carry the names of the authors and should be cited accordingly. The findings, interpretations, and conclusions expressed in this paper are entirely those of the authors. They do not necessarily represent the view of the World Bank, its Executive Directors, or the countries they represent. Policy Research Working Papers are available online at http:/lecon.worldbank.org.

We are grateful to Mary Amiti, Andrew Bernard, Carolyn Evans, James Harrigan, David Hummels, Maurice Schiff, Ravi Yatawara and seminar participants at the Empirical Investigations in International Trade conference at Purdue, the Federal Reserve Board, the University of Delaware, and the World Bank for comments on an earlier draft of this paper. 


\section{Introduction}

Recent literature has emphasized the importance of trade costs for international trade. Anderson and van Wincoop (2003) estimate that trade costs are on average nearly twice as large as production costs, implying that trade costs are important determinants of comparative advantage, perhaps even more important than production costs. Obstfeld and Rogoff (2000) show that trade costs can explain six of the major empirical puzzles that international macroeconomists have struggled with for 25 years. One well-known but little understood trade cost is imposed by the distance a product must travel to reach a market. Understanding how the effect of distance on trade has changed over the last 1520 years will shed some light on why distance is so important, and also on how much technological change can do to reduce the impact of trade costs.

The standard explanation for why distance matters for trade is that transport costs are increasing in distance. Less tangible costs of trade, related to accessing information about foreign markets and finding trade partners, also tend to depress distant trade (Rauch 1999). This suggests that large reductions in transport costs and major improvements in communications technology, such as have materialized since 1980, should generate substantial trade growth and reduce the importance of distance. Indeed, the volume of trade has trebled since 1980 compared with only a 75 percent increase in world real GDP; however, evidence implies that, if anything, distance has become more important for trade.

One way of identifying movements in the effect of distance on trade over time is by comparing estimates of the elasticity of trade to distance from gravity regressions in different years. But results from the large number of international trade studies that 
employ gravity models are not conclusive. Some studies find a decrease in the elasticity of trade to distance, though most point to little change or a modest increase (Disdier and Head 2003). Gravity equation estimates from panel data over long horizons also tend to find an increase (Brun et. al. 2003, Coe et. al. 2003). These results suggests that distance has become more important over the last 40 years.

We seek to contribute to this literature by rigorously analyzing how distance affects trade over time and across industries. While the gravity equation is a useful tool for cross-section analysis, we show that the change in the coefficient on distance over time could be due to misspecification that results from industrial differences in how distance affects trade. In particular, there are vast differences in the distance elasticity of trade across products, implying that the increasing importance of distance might be explained by a shift in the composition of trade toward products with high distance elasticity.

We use bilateral trade data for 766 SITC2 industries in 73 countries reporting $\operatorname{trade}^{1}$ at the 4-digit SITC level to examine whether changes in the composition of trade or changes in the distance elasticity of trade across industries has been responsible for the increased importance of distance since 1985. We find that changes in the composition of trade are relatively unimportant. However, there has been a significant and increasing impact of distance on trade in almost 25 percent of industries. The increase in the elasticity of trade to distance among such a large share of industries suggests that there has been a shift in the relative cost of trade for these industries favoring proximate countries. We also find that homogeneous goods—as defined by Rauch (1999)—are

\footnotetext{
${ }^{1}$ These countries report trade with 196 partners.
} 
about twice as likely to have experienced an increase in the magnitude of the distance coefficient as differentiated goods.

Our results imply that the importance of geography goes well beyond simple iceberg trade costs. Despite large changes in transport and communications costs since 1985, the way in which distance affects trade has not changed for the majority of industries. To the extent that the effect of distance on trade has changed, it has become more important; there are almost no industries for which distance has become significantly less important. These results underscore the need to pursue models in which comparative advantage is tied to both relative trade costs and relative production costs (as in Eaton and Kortum 2002 and Deardorff 2003). Theory must provide a much larger role for geography, and one that is less likely to change unless trade costs approach zero.

This paper is organized as follows. The next section discusses the related literature on the distance effect. Section III offers some stylized facts about distance and trade. Sections IV and V describe out methodology and present results. Section VI explores the effect of regions and preferences on trade growth. Section VII concludes.

\section{The Gravity Model and Related Literature on Distance Effects}

The standard way to estimate the effect of distance on trade is to use the gravity model. The gravity model describes bilateral trade as proportional to the product of the incomes of the two countries and inversely related to the distance between them. In general, gravity results point to an increase in the elasticity of trade to distance. Frankel (1997) finds that a 10 percent increase in distance would have led to about 4 percent less trade in the 1960s and about 7 percent less trade in the 1990s. Moreover, estimates of 
the elasticity of trade to distance from the early twentieth century are similar to what is found today, leading Frankel to comment that "we have more than a century of gravity estimates, and nowhere is there evidence of a decline over time in the distance coefficient" (Frankel 1997, p. 72). Disdier and Head (2003) perform a meta-analysis on estimates of the distance coefficient using data from 51 papers that employ gravity equations. Their results imply that there is an increasing impact of distance on trade on the order of about 20 percent since 1965. In related work, Brun et al. (2002) estimate a panel gravity model over the period 1962-1996 and find that the coefficient on distance has increased in absolute value by 11 percent over the last 35 years.

In contrast, Rauch (1999), also using a gravity equation on data disaggregated by market type, finds that the effect of distance on trade has declined since 1970. Similarly, Leamer and Levinsohn (1995) find that the share of trade between adjacent countries declined from 1970 to 1985 , suggesting distance has become somewhat less importantthough their results exclude income effects. An alternative way to measure integration is by examining relative price movements. Engels and Rogers (1998) examine correlations in relative prices across countries and also find evidence that markets have become more integrated over large distances.

Different explanations for the persistence of distance as a determinant of trade flows abound. Regionalism is the most obvious explanation, but even studies controlling for free trade agreements find an increased importance of distance. Leamer and Storper (2001) argue that personal contact is important, thus the effect of distance will change very little from important advances in communications such as the Internet. ${ }^{2}$ They offer

\footnotetext{
${ }^{2}$ Indeed, Freund and Weinhold 2003 do not find evidence that the Internet has altered the effect of distance on trade.
} 
some anecdotal evidence that major historical improvements have led to only small changes in the distribution of trade. Brun et. al. (2002) argue that infrastructure is to blame. When infrastructure is included in the gravity equation they find a small decrease in the effect of distance on trade over time. However, infrastructure is likely to be driven by trade, so it is not clear that the correlation between infrastructure and trade represents causality. In addition, even inclusive of infrastructure, their results point to very little change in the effect of distance. Coe et. al. (2002) argue that non-linearity is the problem. They estimate a gravity equation with an additive error term and find that there was some decline in the distance coefficient—especially in the 1990s. Evans and Harrigan (2003) show that for the textile industry just-in-time production has become more important, leading retailers to choose proximate countries for the production of socalled "replenishment goods". However, it is unclear whether such concerns have been as important for other industries. Vertical specialization and the composition of imports may also play a role - for example, if imported inputs traded only among proximate countries are responsible for the large increase in trade. There may also be offsetting effects. For example, regionalism will enhance short-distance trade while technological improvements may favor long-distance trade. ${ }^{3}$ Finally, it could simply be a result of persistence in comparative advantage and a decline in transport costs that is unbiased with respect to distance.

A better understanding of whether and how trade has changed over time with respect to distance is necessary before we can state unequivocally why gravity models show so little movement in the distance coefficient. We differ from the previous literature by looking in detail at the industrial composition of the distance effect.

\footnotetext{
${ }^{3}$ For example, Hummels 1999a finds that containerization reduced the relative cost of distant trade.
} 


\section{Some Stylized Facts About Distance and Trade}

The simplest way to describe the effect of distance on trade over time is by calculating the average distance that world trade travels. Average distance, ADIST, is defined as follows:

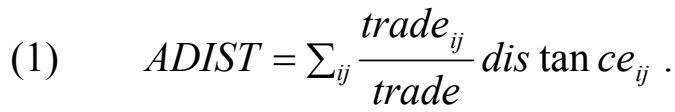

Where trade $_{i j}$ is trade between $i$ to $\mathrm{j}$, trade is total world trade, and distance $e_{i j}$ is distance between $i$ and $j$. ADIST can be calculated at the aggregate level, the country level, or the industry level.

Figure 1 shows the average distance that aggregate trade travels from 1980 to 2000, using import (cif) and export (fob) data from the IMF Direction of Trade Statistics. We include 166 countries that report trade all years in this period. ${ }^{4}$ Both the import and export data show that the average distance that trade travels has declined slightly since 1980. Figure 1 also reports confidence bands of two standard deviations from the mean, showing that the variance has remained roughly constant over this period.

The disparity between imports and exports could explain some of the dispute in earlier work about whether distance is becoming more important. It is generally believed that the import data are more accurate because customs authorities require that imports are carefully recorded. In much of what follows, for parsimony, we report the results using only the import data.

Next, we examine industry-level data since 1985. We use data for 768 industries at the 4-digit SITC Revision 2 level from the COMTRADE database. While the data 
extend back to 1976, the quality of the data in the mid-1970s is very poor - in 1976 only 14 countries report industry data. By 1985, the number of countries reporting disaggregated data increases dramatically to 65 . The sample includes countries reporting data at least 14 years during 1985-2000. The choice of the industries was also guided by the quality of reporting: we kept industries that report fully during the same period. ${ }^{5}$ With these conditions, the sample includes on average 85 percent of world trade. ${ }^{6}$

We use the disaggregated data to look for evidence of compositional shifts or industry trends that would affect total trade. Compositional effects would occur if, for example, the share of trade increases for products that typically trade at a short distance, pulling down average distance. Alternatively, for some industries there may be a trend in distance as, for example, a country increases trade in that product to more distant places.

Figure 2 shows weighted, unweighted, and median average distances for the 769 industries. The weighted distance multiplies the average distance in a given industry by the industry's share of total trade in each year. If a changing composition of imports has large effects on trade, then movements in the weighted and unweighted average distance would not coincide. No matter how we measure distance traveled, these results show that the distance that a typical product travels has remained roughly constant for the last 15 years.

The averaged industry data could obscure important changes within industries that offset each other. For example, it is possible that short-distance and long-distance products both increased their weight in trade, leading to little movement in weighted and un-weighted distance. To examine this issue, we also report the distribution of industry

\footnotetext{
${ }^{4}$ We also tried using all reporters and there were no significant differences.

${ }^{5}$ There are 911 industries in total at the 4-digit level.
} 
distances. Figure 3a shows a histogram with the number of industries trading at each distance over the period. For example, both in 1985 and 2000 the mode is 4,000-5,000 $\mathrm{km}$, with about $25-30$ percent of products trading at this distance. Figure $3 \mathrm{~b}$ is similar, but weights industry-distances by their share of trade. If industry distances remained constant but the share of trade in a short-distance industry increased from 1985 to 2000, it will be reflected as an increase in the share of trade at that distance. To see changes more clearly, Figures $3 \mathrm{c}$ and $3 \mathrm{~d}$ report the change in the fraction of industries or trade from $3 \mathrm{a}$ and $3 \mathrm{~b}$, respectively. They show that more than 40 percent of both products and trade record a change in distance that is less than 10 percent, and about 80 percent of products record a change in average distance of less than 20 percent. The percentage point change in average distance is centered between zero and -10, implying that somewhat more products show a decrease in average distance than an increase. The industry data also highlight large cross-sectional differences in average distances, which are far more extreme than time-series variation. While a few products trade on average at only $2,000 \mathrm{~km}$, others trade on average at more than $10,000 \mathrm{~km}$.

Examining averages is useful for summarizing the data, but there are three problems with these measures. One, averages are highly driven by the large trade flows between industrial countries and thus conceal important changes in trade flows that have occurred between small countries because their weight in trade is so small. ${ }^{7}$ Two, averages do not account for changes in income and other factors that affect the distribution of trade. Three, averages obscure important variation in trade by distance within industries that might offset each other.

\footnotetext{
${ }^{6}$ The minimum sample coverage is 83 percent and the maximum is 87 percent.
} 
The first two concerns are addressed in the next section. To address the last point, we test whether the observed distribution of trade according to distance in the early part of the sample is drawn from the same distribution as in the later part of the sample. For each industry we calculate the average share of trade that falls into distance intervals set $500 \mathrm{~km}$ apart for the 1985-989 and 1995-2000 periods. We use the Wilcoxon MatchedPairs Signed-Ranks Test to determine whether the distance distribution of trade by has changed significantly between these periods. The null hypothesis is that the difference between the share of trade in each period has a median value of zero. The advantage of this test as compared to other tests is that it does not impose any distribution on the data, so it is especially useful when the distribution is unknown, as in the case of the distribution of distance.

We find that for 18 percent of the industries we can reject that the pattern of trade according to distance is drawn from the same distribution. Thus, while the distribution of trade by distance has remained roughly stable for the majority of industries, there are some industries for which the effect of distance has changed markedly.

\section{Methodology}

Examining average distances and the distribution of trade by distance helps us understand the texture of the data, but such measures do not control for the standard determinants of trade. In this section, we describe our methodology for examining changes in the elasticity of trade to distance. First, we illustrate the problems that stem from aggregation in a gravity model. We then describe our technique for evaluating the

\footnotetext{
${ }^{7}$ Carrere and Schiff (2004), for instance, find vast differences in the movements in average distances between countries.
} 
change in the elasticity of distance on trade using bilateral trade data at the aggregate and industry level. We also discuss the decomposition of the average elasticity into the part due to a change in the composition of trade and a part due to change in the elasticity among industries.

To illustrate the aggregation problem arising from a gravity model, we use a simple example with varying industry distance effects. Assume we can write a gravity equation for imports in product $k$, by country $i$ from country $j$, at time $t$ as

$$
T R A D E_{i j, t}^{k}=A_{t}^{k} \frac{G D P_{i}^{\alpha} G D P_{j}^{\beta}}{D I S T A N C E_{i j}^{\gamma_{k}+\delta_{t}}},
$$

where $\mathrm{A}_{\mathrm{t}}{ }^{\mathrm{k}}$ is a constant that reflects how important that product is in consumption and varies by product and by time, $\gamma_{k}$ is a product-specific component of the effect of distance on trade, and $\delta_{t}$ is a time-specific component $\left(\gamma_{k}>0, \delta_{t}>0\right)$. The wide variation in average distances by industry shown above suggests that the elasticity of trade to distance does in fact vary substantially by product (a fact which we will confirm below). We assume that the time-specific component $\delta_{t}$ is common across products for ease of exposition, though we relax this assumption in the estimation. If the effect of distance is decreasing over time then $\delta_{t}$ will fall over time.

Summing equation (2) over all products yields total trade between countries $i$ and $j$,

$$
\operatorname{TRADE}_{i j, t}=k G D P_{i}^{\alpha} G D P_{j}^{\beta} \operatorname{DISTANCE}^{-\delta_{t}} \sum_{k} \frac{A_{t}^{k}}{\operatorname{DISTANCE}_{i j}^{\gamma_{k}}} .
$$

Thus, the log of aggregate bilateral trade can be written as a function of income and distance as follows: 
(4) $\ln T R A D E_{i j, t}=K+\alpha \ln G D P_{i}+\beta \ln G D P_{j}-\delta_{t} \ln D I S T A N C E_{i j}+\ln \left(\sum \frac{A_{t}^{k}}{D I S T A N C E_{i j}^{\gamma_{k}}}\right)$.

But, the standard gravity equation, which is estimated on aggregate trade data is

$$
\ln \text { trade }_{i j}=K+\alpha \ln G D P_{i}+\beta \ln G D P_{j}+\gamma \ln D I S T A N C E_{i j}+\varepsilon_{i j} .
$$

This implies that the estimated coefficient on distance is biased, and that it makes little sense to compare the coefficients on distance in gravity equations over different periods. The problem is twofold. First, the equation is misspecified, distance does not enter log linearly in a bilateral trade equation. Second, if the importance of some industries is changing over time - the $A^{\mathrm{k}} \mathrm{s}$ are changing - the coefficient on distance will change, even if the elasticity of trade for each industry remains constant.

The increase in the importance of distance suggested by gravity estimates could therefore be due to an increase in the share of trade accounted for by distance-sensitive products, by an increase in the elasticity of trade to distance for a relatively large number of industries, or simply to misspecification. We refer to the trade-share movements as the compositional effect, and the change in distance elasticities among industries as the distance-sensitivity effect. Our goal is to estimate the contribution of these two effects to the change in the aggregate distance coefficient.

To decompose the change in the elasticity of trade to distance into these two components, we start by defining $\gamma_{t}^{k}$ as the distance elasticity of trade of industry $k$ at period $t$. The average-distance elasticity for all industries, $\gamma_{t}$, is thus

$$
\gamma_{t}=\sum_{k} \operatorname{share} e_{t}^{k} \gamma_{t}^{k}
$$

Where share $_{t}^{k}$ is industry $k^{\prime}$ s share in total trade at time $t$. 
We estimate separately the distance elasticity for each industry at the start and end of the sample, $\gamma_{1}^{k}$ and $\gamma_{2}^{k}$, using the following regression equation:

$$
\operatorname{trade}_{i j}^{k}=\alpha_{i}^{k}+\alpha_{j}^{k}+\gamma^{k} d i s \tan c e_{i j}+\varepsilon_{i j}^{k},
$$

where trade and distance are in logs. The $\alpha s$ are country fixed effects, and $\varepsilon$ is an error term that is assumed to be iid. This is similar to using an industry-gravity model, such as equation (2), but it is more general because country effects will also capture important determinants of trade besides income, such as openness, comparative advantage, and multilateral resistance. In addition, for industry data they are more sensible than income because they will do a better job of controlling for demand and export supply by product. The coefficient on distance is the elasticity of trade to distance. To calculate $\gamma_{1}$ and $\gamma_{2}$ we simply weight the estimated distance coefficients by trade shares in each period.

Totally differentiating equation (6) yields,

$$
d \gamma_{t}=\sum_{k} d s h a r e_{t}^{k} \gamma^{k}+\sum_{k} \operatorname{share}_{t}^{k} d \gamma_{t}^{k}
$$

The first term on the right hand side of equation (8) is the compositional effect and the second term is the distance-sensitivity effect.

We calculate the compositional effect using the average distance elasticity in each industry over the whole period. To estimate the average $\gamma^{\mathrm{k}}$ for each industry we estimate equation (7) using all data and country-time and partner-time fixed effects, i.e. the equation we estimate is

$$
\operatorname{trade}_{i j, t}^{k}=\alpha_{i t}^{k}+\alpha_{j t}^{k}+\gamma^{k} d i s \tan c e_{i j}+\varepsilon_{i j t}^{k} .
$$

To estimate the change in $\gamma$ we allow for a time-varying distance coefficient and first difference equation (7). Since we are working with two periods we could also 
simply compare $\gamma_{1}^{k}$ and $\gamma_{2}^{k}$, the advantage of using the single regression is that we can more easily compute general statistics by industry.

$$
\operatorname{trade}_{i j, t}^{k}-\operatorname{trade}_{i j, t-1}^{k}=\left(\alpha_{i t}^{k}-\alpha_{i t-1}^{k}\right)+\left(\alpha_{j t}^{k}-\alpha_{j t-1}^{k}\right)+\left(\gamma_{t}^{k}-\gamma_{t-1}^{k}\right) d i s \tan c e_{i j}+\left(\varepsilon_{i j t}^{k}-\varepsilon_{i j t-1}^{k}\right) \text {. }
$$

This yields a straightforward estimating equation:

$$
\operatorname{gtrade}_{i j, t}^{k}=\beta_{i t}^{k}+\beta_{j t}^{k}+\eta_{t}^{k} d i s \tan c e_{i j}+\mu_{i j t}^{k},
$$

where gtrade is trade growth. The $\eta$ s gives an estimate of $d \gamma$ in equation (8), which represents whether trade growth is biased toward more distant countries. It is the percentage point change in annual trade growth for a percentage change in distance. For example, if $\eta$ is -.1, it would imply that 10 percent increase in distance between two countries leads to 1 percentage point slower trade growth.

In order to provide a benchmark, we also estimate equations (7) and (11) using the aggregate bilateral trade data. This allows us to compare the average industry distance elasticity with the distance elasticity from aggregate data.

\section{Regression Results}

We use data on the value of bilateral trade for 766 SITC2 industries. ${ }^{8}$ Within the industries, we calculate average bilateral trade for three periods, 1985-89, 1990-1994, 1995-2000. Using averaged data should reduce problems due to idiosyncratic shocks to an industry in any given year or exchange rate fluctuations. We restrict the sample to be a balanced sample. This has an advantage in making the data directly comparable across periods, but a disadvantage because we are excluding new trade that may be more or less

\footnotetext{
${ }^{8}$ Here we dropped two industries that did not have enough observations to estimate a distance coefficient.
} 
biased toward distant partners than existing grade. As a robustness test, we complement the results using aggregate bilateral data, which includes all trade between two partners.

First, we estimate the levels regression to determine the average distance elasticity for each industry over the whole period. We use average trade for the three periods (1985-1989, 1990-1994, and 1995-2000) and regress the log of average bilateral trade in each industry on country-time and partner-time fixed effects and log distance (equation 9). ${ }^{9}$ Country-time fixed effects capture all country-specific determinants of trade growth, including income and trade policy, as well as changes in multilateral resistance that might otherwise bias our results. ${ }^{10}$ Figure 4 shows the distribution of the distance coefficients. They are centered around -1.3 and the distribution is surprisingly normal.

We calculate an average distance elasticity by weighting the average distance coefficient in each period by its share of trade. We then decompose change in the average distance elasticity into that due to the change in the industry distance coefficients (the distance sensitivity effect) and that due to the changes in trade shares (the compositional effect). The results are reported in Table 1. Panel (a) shows the decomposition. Overall, trade growth was biased toward shorter distances - the distance coefficient increased in magnitude by 0.135 (Column 3 ). The distance-sensitivity effect fully accounts for the increase in the importance of distance, while the composition effect

\footnotetext{
${ }^{9}$ We also include dummies for border, language, and preferential trade agreements. These were not significant in most industries, and did not alter the results on the distance coefficient or the tabulations. It is not too surprising since while these are likely to have level effects, it is not clear they will have growth effects. In the aggregate bilateral trade equation, the dummy for preferential trade agreements is positive and significant, but its magnitude is small, leaving the result on distance unchanged (see Berthelon and Freund 2004).

${ }^{10}$ In a well known paper, Anderson and van Wincoop (2003) show that gravity results on national border effects are biased because they omit a theoretically important "multilateral resistance" term. Theory implies that bilateral trade is decreasing in the size of bilateral trade barrier relative to the average trade barrier of the two parties to trade with all partners. In terms of distance, this implies that neighboring countries may be more pushed to trade with each other if they are very far from the rest of the world
} 
is positive and almost nil. The composition effect is small because changes in trade shares are minute over this period and are distributed tightly around zero; in more than 90 percent of industries the change in trade shares is less than .1 percentage points over the period. This finding is quite striking, given changes that we might expect to take place in comparative advantage over time the vast majority of trade shares are roughly constant. These results imply that there is a change in relative trade costs that is affecting many industries, and making distance more important.

Panels $\mathrm{b}$ and $\mathrm{c}$ show the average coefficients on distance in the first and last period for the industry data and the aggregate data, respectively. The weighted-average coefficients from the industry data are somewhat lower than the distance coefficients from the aggregate data, in both periods. The specifications are somewhat different since industry coefficients allow a different country fixed effect for each industry, while when we use the aggregate data there is only one coefficient per country-time period. Still, the change in the coefficients from the first to the last period is quite similar. The industry data suggest a change of about 0.13 while the aggregate data suggest the change is about 0.11 .

Table 2 reports tabulations of the results when the trade growth regression (equation 11) is estimated for each of the 766 industries individually, using country-time and partner-time fixed effects, over the change from the first five-year period to the last period. For nearly 30 percent of industries and about 37 percent of trade, the coefficient is negative and significant (columns 2 and 3), while for almost 70 percent of industries the coefficient is not significant. There are only a handful of industries for which the sign is positive and significant. Columns 4 and 8 record the average coefficient and the 
weighted-average coefficient for each group. As shown in the bottom row, there is evidence of an increase in the effect of distance on trade when we average over all industries. Specifically the coefficients suggest that trade growth was biased toward proximate countries. The average coefficients are -.10 to -.14 . They imply that over the whole period, from 1985 to 2000 , the distance elasticity of trade increased by .10 to .14 percentage points.

Next, for comparison purposes, we estimate the effect of distance on trade growth using data on bilateral aggregate merchandise trade from 1980-2000. The results are reported in Table 3. In this case we use five-year trade growth, in order to allow countries that entered in each period to be part of the sample. We show the results for three samples: (i) all available data, (ii) full reporters, which includes only countries that report trade in all periods, but allows for new partners over time, and (iii) a balanced sample. They include 180, 125, and 112 reporting countries, respectively. The balanced sample is most comparable to the industry sample, since by definition both exclude trade with new partners. Comparing results from the different samples is therefore important in order to ensure that new partners do not have a large effect on the results.

The coefficient on distance is always negative and significant, irrespective of the sample. Thus, similar to gravity results, we find evidence that trade growth has been biased toward shorter distances. The coefficient from the balanced sample is somewhat higher than from the others but all are very similar, indicating that the increase in the importance of distance is widespread and not just a function of excluding new partners. The coefficient distance from the 5-year growth regressions ranges from-.05 to -.07, implying a increase in the magnitude of the elasticity of trade to distance of about .15-.21 
since 1980 (or .10 to .14 for the $1985-2000$ period), consistent with the results presented above and previous results from gravity models.

\section{Industry Results}

Our results imply that there has been an increase in the importance of distance for a large share of industries. In this section, we examine which sectors and type of goods have been subject to these shifts. First, we look at the industries at the one-digit SITC level. Second, we split the data by market structure. We use the Rauch (1999) classifications, which split goods into three categories (i) those traded on an organized exchange, (ii) reference priced goods, and (iii) all other commodities. The first two categories are meant to capture goods which are roughly homogeneous, the third category is primarily differentiated goods — goods where brand and producer are relatively more important.

Table 4 reports results for the goods at the one-digit SITC level. For all categories, a greater share of industries display a bias toward an increasing importance of distance (negative coefficient) than towards a decreasing importance of distance (positive coefficient). The increase in the elasticity is especially important for animals, food and live animals, chemicals, and other goods. In terms of the total number of goods that show a negative and significant change in the elasticity, basic manufactures, chemicals and food and live animals are most important. Crude materials and mineral fuels show very little change in their sensitivity to distance in terms of the percentage of industries that are negative and significant. In part, this may be because production of these products is determined largely by natural resources, and as a result, production and trade are changing only marginally over time. In addition, in the case of mineral fuels, this 
may be because they are already very sensitive to distance, as shown by the high average distance elasticity of -1.55 .

Table 5 reports results for the goods split by the Rauch classifications. We find that organized exchange and reference priced goods have become more distance sensitive than differentiated goods. According to the liberal classification, nearly half of the goods trading on an organized exchange have become significantly more sensitive to distance. In addition, the average coefficient on distance from the trade growth regression, -0.26 , is much larger in magnitude than the average coefficient on differentiated goods. This means that relatively more homogeneous industries have become distance sensitive and they have become distance sensitive to a greater extent than differentiated goods. This is consistent with the Rauch's (1999) hypothesis that communications improvements that reduce transactions costs have had a greater impact on trade in differentiated goods than on trade in homogeneous goods.

\section{Conclusions}

We systematically examine bilateral trade data to look for evidence of a change in the effect of distance on trade. Results from regressions using aggregate bilateral data imply that distance has become more important since 1980. Using industry data, we find that compositional shifts do not explain the increase in the importance of distance. The increasing importance of distance is due to increasing distance sensitivity in about 25 percent of industries. In contrast, we find that only a handful of industries have become less sensitive to distance. We also find that homogeneous goods are more likely to display an increasing importance of distance than differentiated goods. One explanation 
is that improved communications help reduce search costs, which are relatively more important for differentiated goods. However, the results offer no evidence of the "death of distance," rather they suggest that distance-related relative trade costs have remained unchanged for most industries and shifted in favor of proximate markets for some industries. 


\section{References}

Anderson, J. and E. van Wincoop (2003a) "Gravity with Gravitas: A Solution to the Border Puzzle” American Economic Review, 93, 170-192.

Anderson J. and E. van Wincoop (2003b) "Trade Costs" mimeo, prepared for the Journal of Economic Literature.

Berthelon, M. and C. Freund (2004) “Regional Borders Matter” World Bank, mimeo.

Brun, J., Carrere, C. P Gillaumont, J. de Melo (2003) "Has Distance Died? Evidence from a Panel Gravity Model” Mimeo, Universite d'Auvergne."

Carrere, C. and M. Schiff (2004) "On the Geography of Trade: Distance is Alive and Well” World Bank Policy Research Working Paper 3206.

Coe, David, Arvind Subramanian, Natalia Tamirisa, and Rikhil Bhavnani (2002) "The Missing Globalization Puzzle” IMF Working Paper 02/171.

Deardorff, A. (2003) "Local Comparative Advantage Trade Costs and the Pattern of Trade" Mimeo, University of Michigan.

Disdier, A and K. Head (2003) "Exaggerated Reports on the Death of Distance: Lessons from a Meta-Analysis” Mimeo, Sorbonne.

Eaton and Kortum (2002) “Technology, Geography and Trade" Econometrica, 2002, 70(5), 1741-1779.

Engel, Charles and John Rogers (1998) "Regional Patterns in the Law of One Price: The Role of Geography versus Currencies." In J. Frankel Editor, The Regionalization of the World Economy, The University of Chicago Press.

Evans, C. and J. Harrigan (2003) “Distance, Time and Specialization” NBER Working Paper \# 9729.

Hummels, D. (1999a) "Have International Transport Costs Declined” Mimeo, University of Chicago.

Hummels, D. (1999b) “Toward a Geography of Trade Costs” Mimeo, University of Chicago.

Frankel (1997) Regional Trading Blocs in the World Economic System. Institute for International Economics, Washington D.C.

Freund, C. and D. Weinhold (2003) "The Effect of the Internet on International Trade" Journal of International Economics, forthcoming. 
Leamer E. and J. Levinsohn (1995) "International Trade Theory: The Evidence" in Handbook of International Economics, Elsevier: North Holland.

Leamer E. and M. Storper (2001) “The Economic Geography of the Internet Age” NBER Working Paper 8450.

Obstfeld, M. and K. Rogoff (2000) "The Six Major Puzzles in International Macroeconomics. Is there a Common Cause?", in B.S. Bernanke and K. Rogoff, eds. NBER Macroeconomics Annual 2000. Cambridge: MIT Press, 2000, 339-390.

Rauch, J. (1999) "Networks versus Markets in International Trade" Journal of International Economics 48, 7-35. 
Figure 1. Average Distance Traveled by Trade (1980-2000)

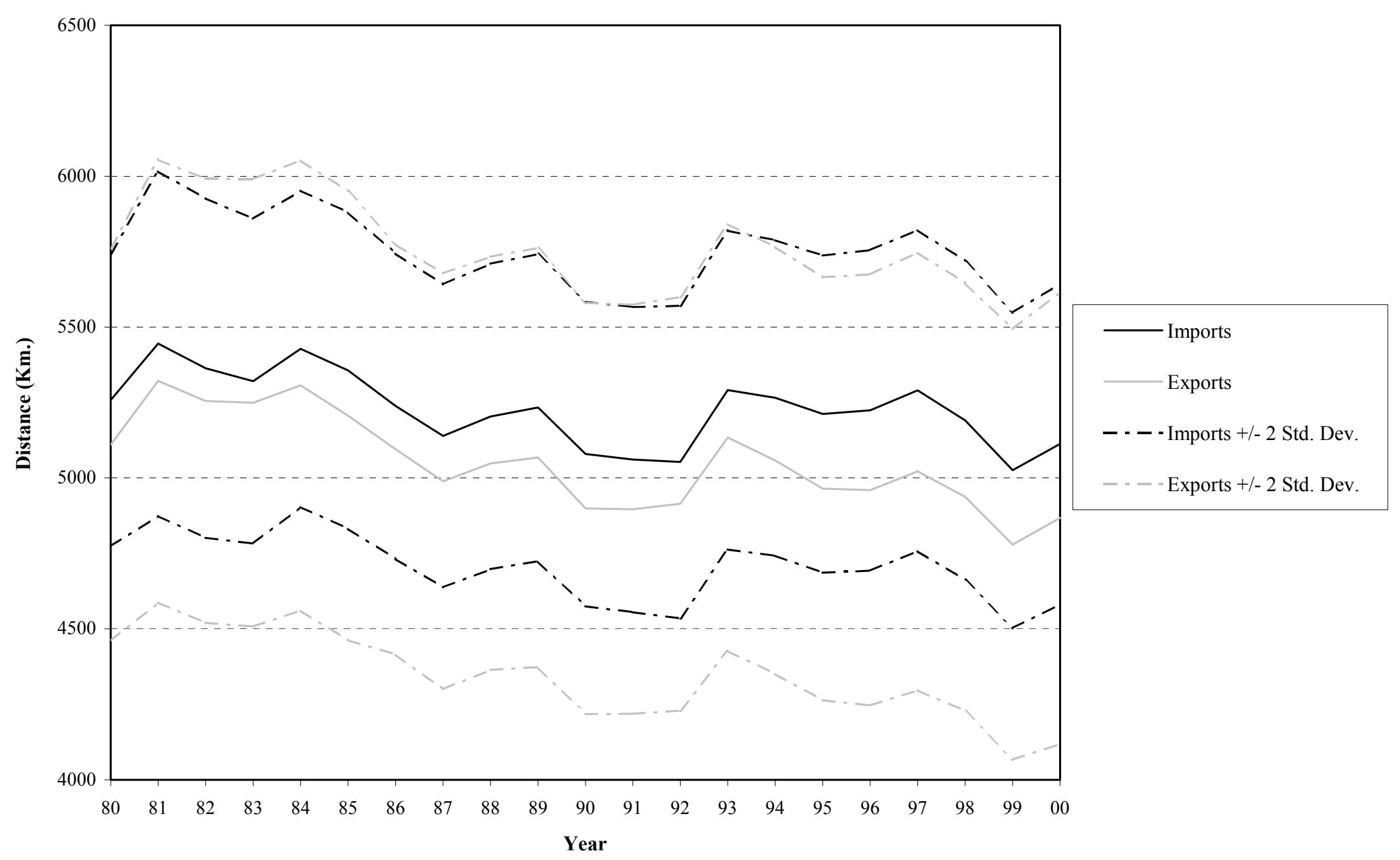

Source: Authors' calculations using DOTS data. Includes 166 countries. 
Figure 2. Average and Median Distance Traveled by Imports using Industry Data (1985-2000)

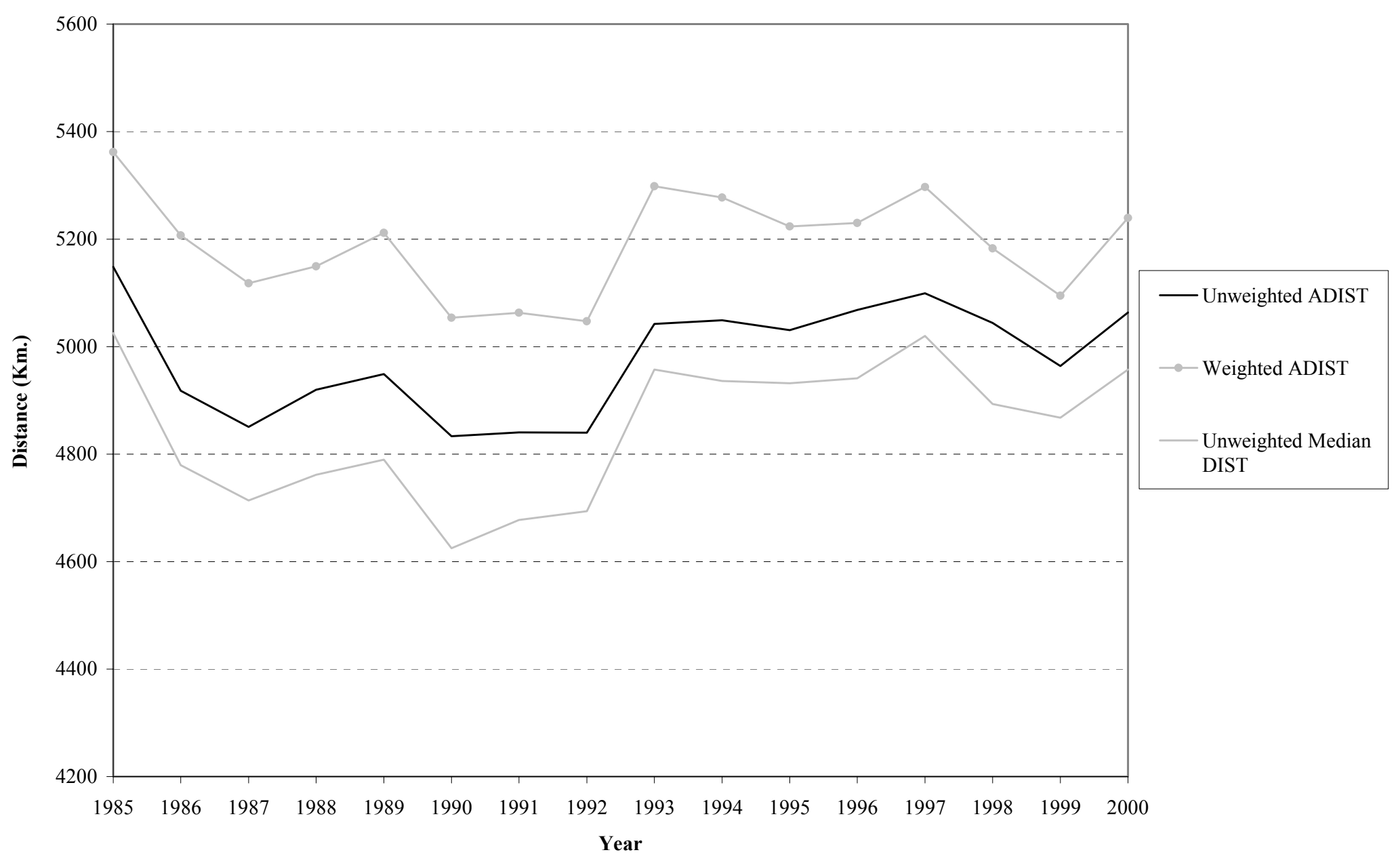

Source: Authors' calculations using COMTRADE data. 
Figure 3a. Distance Distribution of Number of Industries (1985-2000)

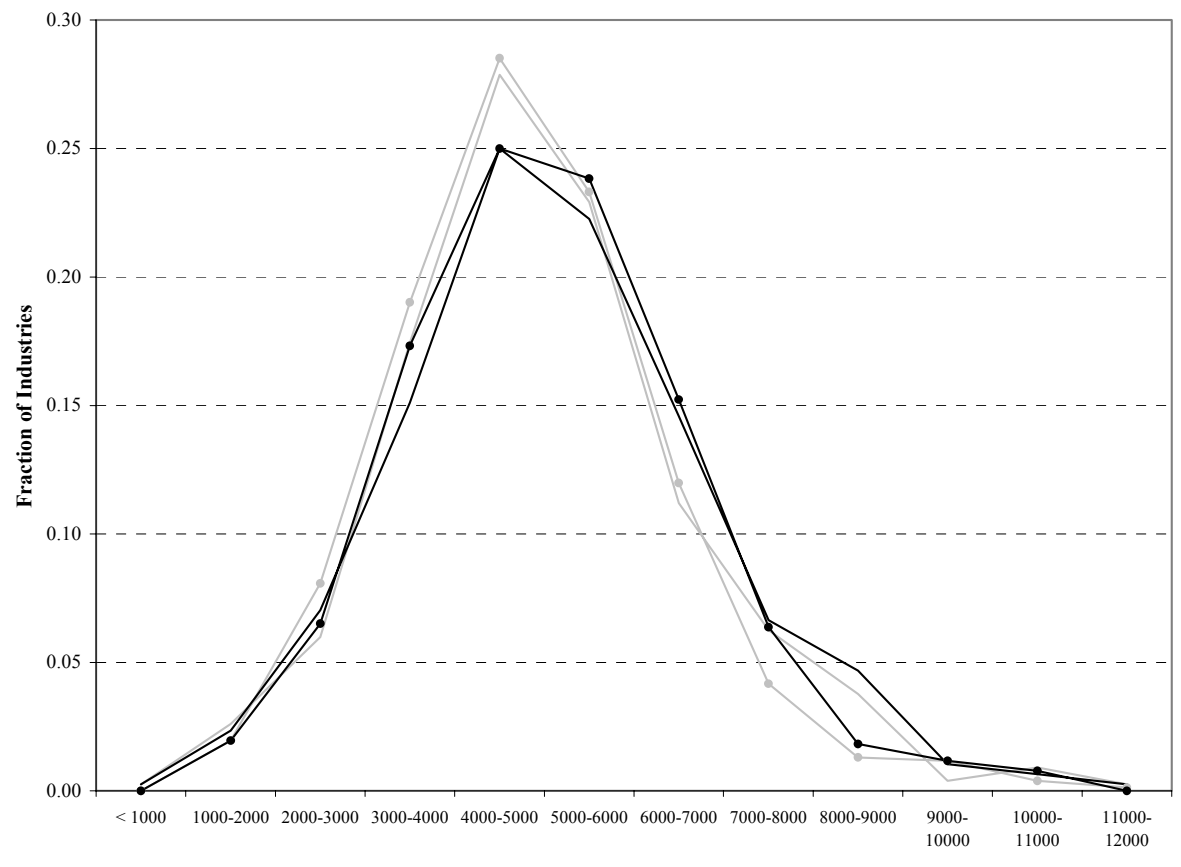

Exports 198

$\rightarrow$ Exports 2000

- Imports 1985

$\rightarrow-$ Imports 2000

Source: Authors' calculations using COMTRADE data.

Figure 3b. Distance Distribution of Trade Share (1985-2000)

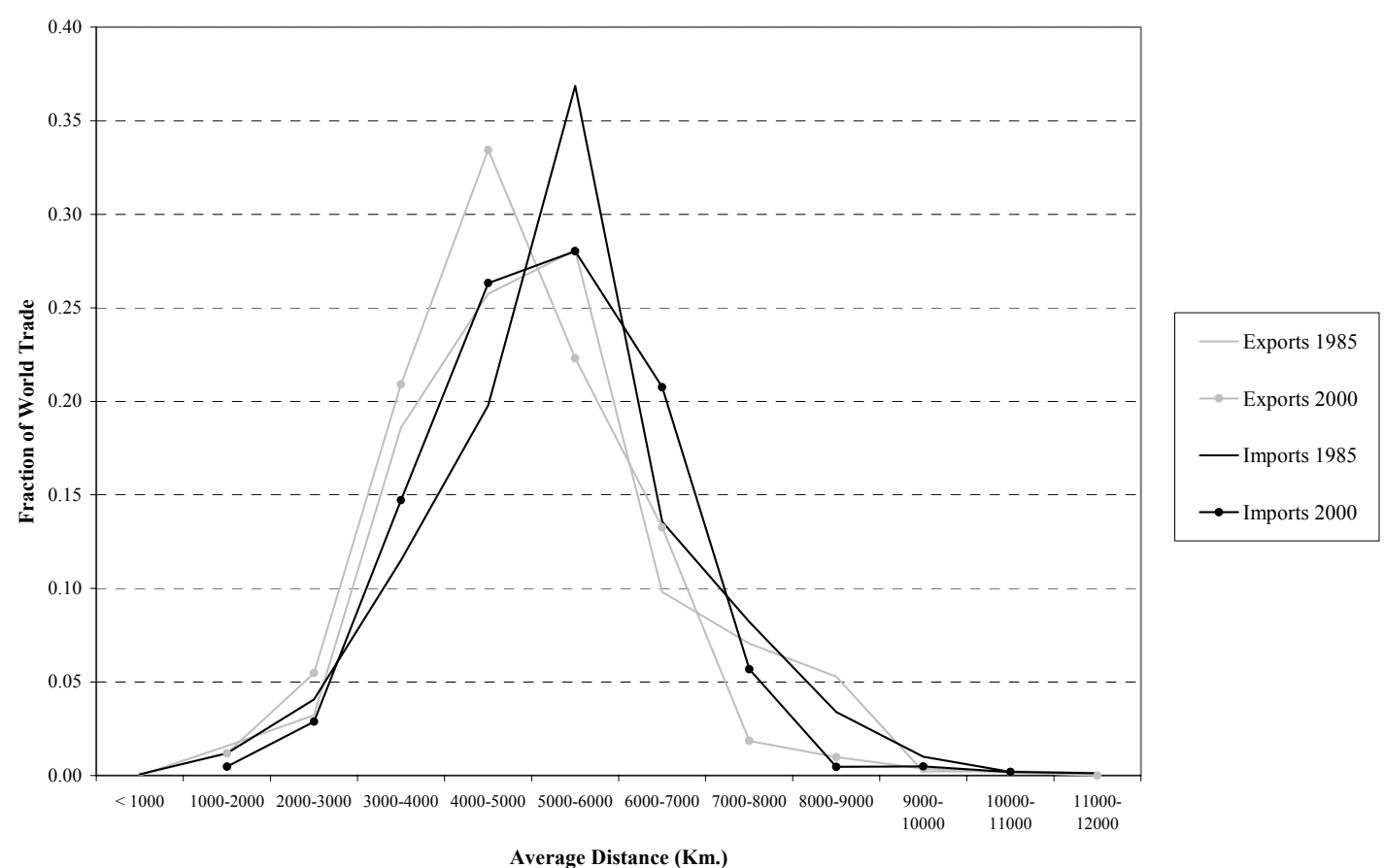

Source: Authors' calculations using COMTRADE data. 
Figure 3c. Density (Fraction of Industries) of Change in Industry ADIST between 1985 and 2000

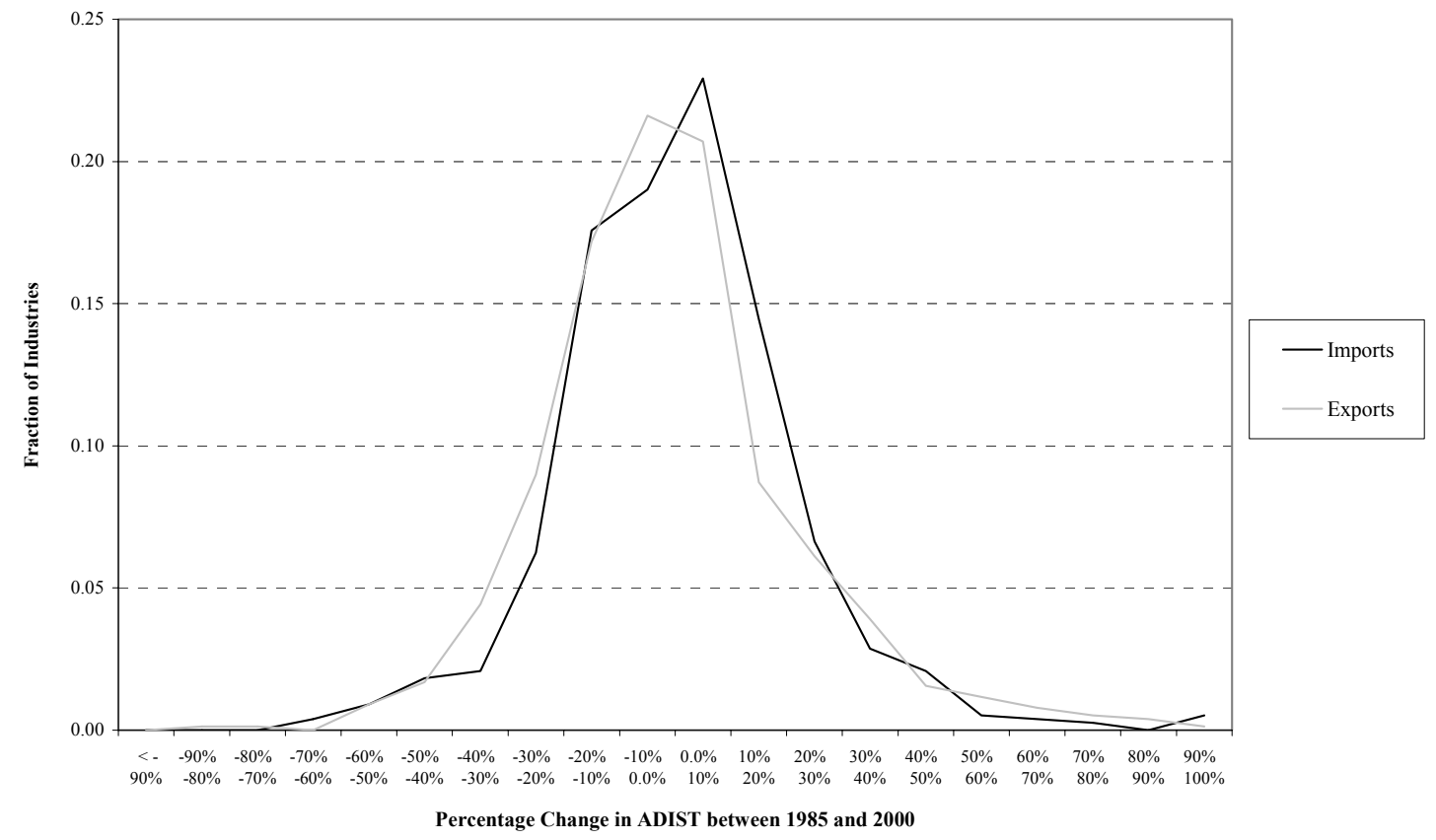

Source: Authors' calculations using COMTRADE data.

Figure 3d. Density (Fraction of World Trade) of Change in Industry ADIST between 1985 and 2000

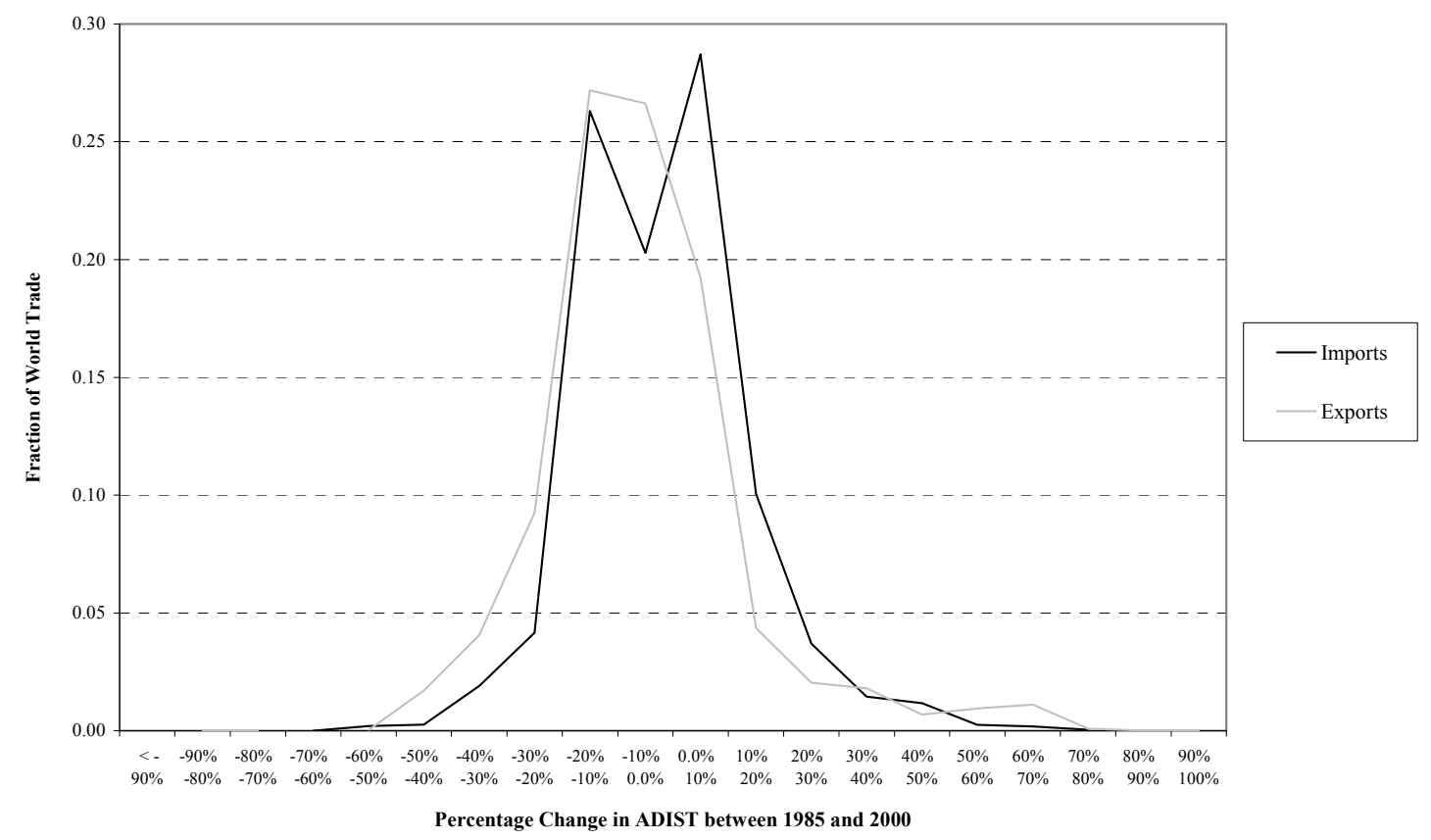

Source: Authors' calculations using COMTRADE data. 
Figure4. Distribution of Industry Distance Coefficent (1985-2000)

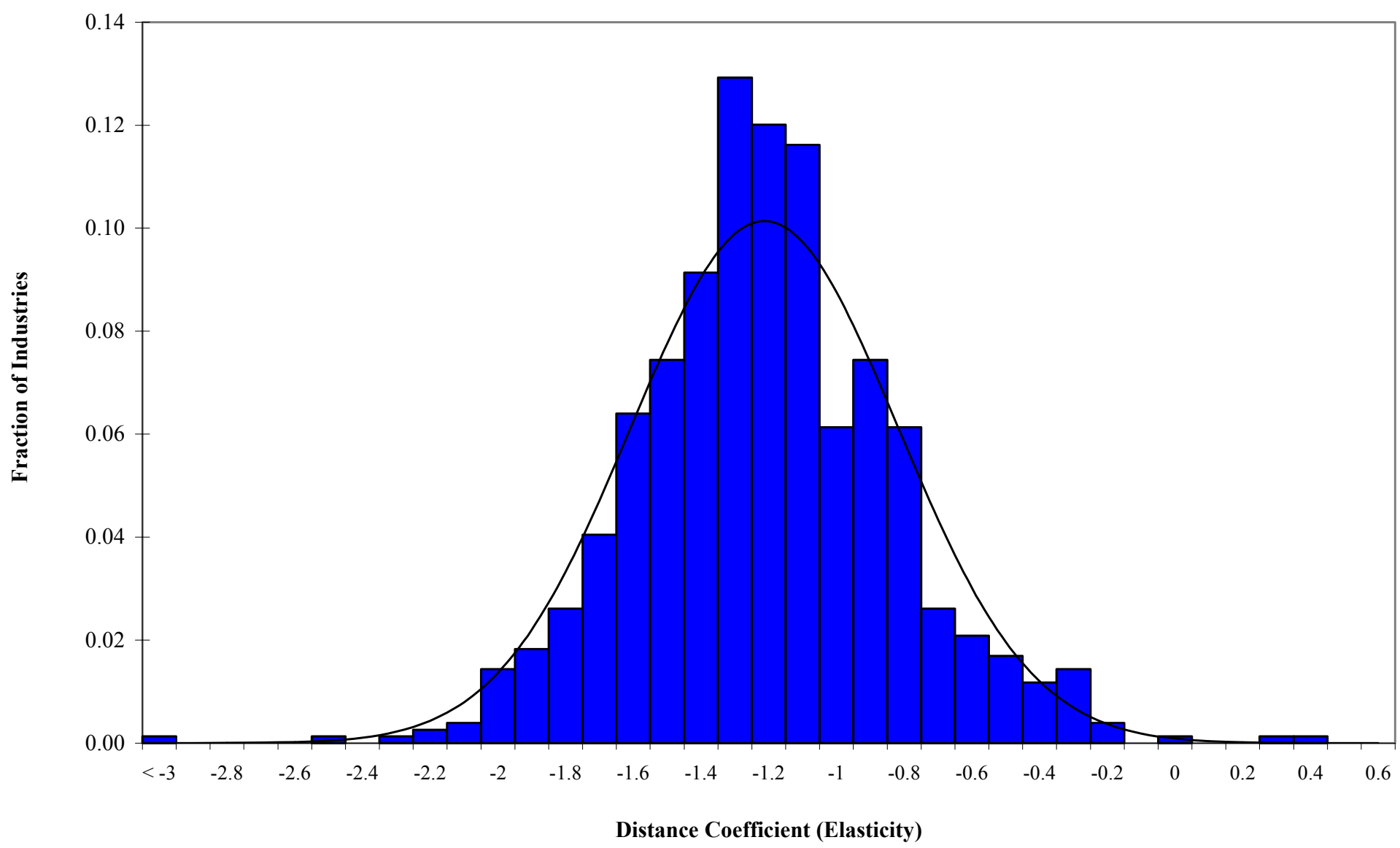

Source: Authors' calculations using COMTRADE data. 766 industries.

Coefficients from five-year averages trade level regressions including reporter-time and partner-time fixed effects. 
Table 1: The Decomposition of Distance Coefficient**

a. Distance-Sensitivity Effect and Compositional Effect**

\begin{tabular}{ccc}
\hline$(1)$ & $(2)$ & $(3)$ \\
Distance-Sensitivity Effect & Compositional Effect & Total \\
\hline$\sum_{k}\left(\Delta \gamma_{k} *\right.$ Share $\left._{k}\right)$ & $\sum_{k}\left(\gamma_{k}^{*} \Delta\right.$ Share $\left._{k}\right)$ & $\Delta \gamma$ \\
\hline-0.1360 & 0.0012 & -0.1348 \\
\hline
\end{tabular}

** Data source: COMTRADE of all Industries (766) that report 14 out of 16 years during 1985-2000. $\gamma_{k}$ is the coefficient of industry $k$ over the $1985-2000$ period using five-year averages. $\Delta \gamma_{k}$ is the change of the distance coefficient. Share ${ }_{k}$ is the average share of world trade of industry $k$ over the same period and $\Delta$ Share $_{k}$ is the change in the industry share.

\section{b. Distance Coefficient of Import Regressions using Aggregate Data*}

\begin{tabular}{lcc}
\hline & $(1)$ & $(2)$ \\
& $1985-1989$ & $1995-2000$ \\
\hline Distance Coefficient & -1.498 & -1.606 \\
& $(0.0241)$ & $(0.0231)$ \\
\hline
\end{tabular}

Robust standard errors statistics in parentheses

* Data source: DOTS data of countries reporting all years during the period.

\section{c. Distance Coefficient of Import Regressions using Industry Data**}

\begin{tabular}{lcc}
\hline & $(1)$ & $(2)$ \\
& $1985-1989$ & $1995-2000$ \\
\hline Distance Coefficient & -1.300 & -1.435 \\
\hline
\end{tabular}

** Weighted average coefficient of all Industries (766) that report 14 out of 16 years during 1985-2000.

Data source: COMTRADE 
Table 2. Summary Statistics of Five-Year Average Log Distance Coefficient on by Industry Imports Growth Regressions, 1985-2000*

Summary Statistics of Five-Year Average Log Distance Coefficient on by Industry Growth Regressions, $1985-2000$ (1985-1989 and 1995-2000)

\begin{tabular}{|c|c|c|c|c|c|c|c|c|}
\hline \multirow[t]{2}{*}{ Sign and Significance } & $\begin{array}{c}\text { Number of } \\
\text { Industries }\end{array}$ & $\begin{array}{c}\text { Percentage } \\
\text { Industries }\end{array}$ & $\begin{array}{c}\text { Percentage } \\
\text { Trade }\end{array}$ & $\begin{array}{c}\text { Average } \\
\text { Coefficient }\end{array}$ & $\begin{array}{l}\text { Standard } \\
\text { Deviation }\end{array}$ & Minimum & Maximum & $\begin{array}{c}\text { Weighted Av. } \\
\text { Coefficient }\end{array}$ \\
\hline & $(1)$ & (2) & (3) & (4) & $(5)$ & $(6)$ & (7) & $(8)$ \\
\hline Pos \& Sig (95\%) & 19 & 2.5 & 1.0 & 0.242 & 0.094 & 0.119 & 0.509 & 0.217 \\
\hline Neg \& Sig (95\%) & 224 & 29.2 & 36.9 & -0.270 & 0.160 & -1.144 & -0.104 & -0.230 \\
\hline Pos \& Insig (95\%) & 186 & 24.3 & 14.3 & 0.111 & 0.147 & 0.000 & 1.151 & 0.057 \\
\hline Neg \& Insig (95\%) & 337 & 44.0 & 47.8 & -0.131 & 0.219 & -2.621 & -0.001 & -0.129 \\
\hline Total & 766 & 100.0 & 100.0 & -0.104 & 0.238 & -2.621 & 1.151 & -0.136 \\
\hline
\end{tabular}

* Data source: COMTRADE data of all Industries with data in all years for the 1985-2000 period (766 industries).

Regressions are robust to heteroscedasticity and include Reporter-Time and Partner-Time fixed effects. 
Table 3. Five-Year Average Imports Growth Regressions, 1980-2000*

\begin{tabular}{lrrr} 
& \multicolumn{1}{c}{$(1)$} & $(2)$ & $(3)$ \\
& All Data & Full Reporters & FR Balanced Sample \\
\hline Log Distance & -0.0548 & -0.0503 & -0.0659 \\
& $(0.0085)^{* *}$ & $(0.0089)^{* *}$ & $(0.0092)^{* *}$ \\
\hline Observations & 51,882 & 44,427 & 28,622 \\
R-squared & 0.12 & 0.12 & 0.15 \\
F-stat & 6.07 & 5.69 & 5.1 \\
\hline
\end{tabular}

Robust standard errors statistics in parentheses, $*$ significant at $5 \%$; ** significant at $1 \%$

* Data source: DOTS. All data refers to all positive trade data observations.

Full Reporters are countries that report data all years during the period.

All regressions include Reporter-Time and Partner-Time fixed effects. 
Table 4. Sign and Significance of Log Distance Coefficient on Industry Growth Regressions by Industries at the 1-Digit Level, 1985-1989 and 1995-2000*

All Industries

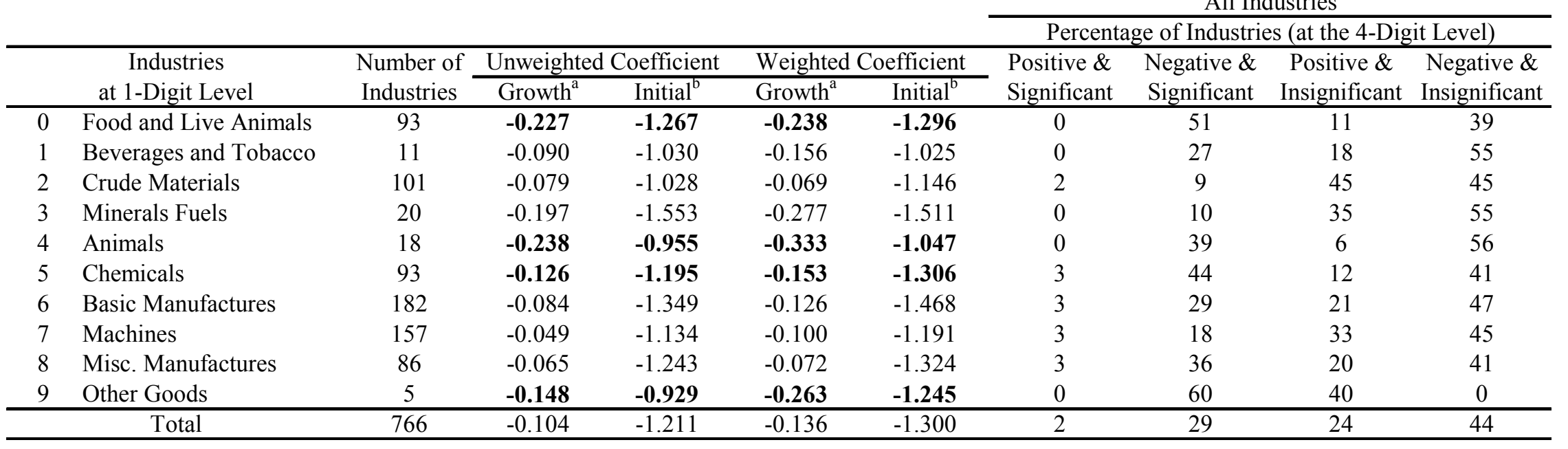

*Significant at the $95 \%$ level

Rauch classified industries include $70 \%$ of trade accounted for the above 766 industries.

${ }^{a}$ Coefficient from growth regresions for the 1985-2000 period.

${ }^{\mathrm{b}}$ Coefficient from level regressions for the 1985-1989 period (initial 5-year period). 
Table 5. Sign and Significance of Log Distance Coefficient on Industry Growth Regressions

by Rauch Classification of Goods, 1985-2000

\begin{tabular}{|c|c|c|c|c|c|c|c|}
\hline \multirow[b]{3}{*}{ Goods Type } & \multicolumn{7}{|c|}{ "Conservative" Classification } \\
\hline & \multirow{2}{*}{$\begin{array}{l}\text { Number of } \\
\text { Industries }\end{array}$} & \multicolumn{2}{|c|}{ Average Coefficient ${ }^{\mathrm{a}}$} & \multicolumn{4}{|c|}{ Percentage of Industries } \\
\hline & & Growth & Level & Pos \& Sig & Neg \& Sig & Pos \& Insig & Neg \& Insig \\
\hline Organized Exchange & 59 & -0.293 & -1.340 & 0 & 36 & 17 & 47 \\
\hline Reference Priced & 136 & -0.164 & -1.428 & 0 & 30 & 23 & 47 \\
\hline Differentiated & 256 & -0.088 & -1.347 & 3 & 25 & 23 & 49 \\
\hline \multirow[t]{3}{*}{ Total } & 451 & -0.142 & -1.388 & 2 & 28 & 22 & 48 \\
\hline & \multicolumn{7}{|c|}{ "Liberal" Classification } \\
\hline & Number of & \multicolumn{2}{|c|}{ Average Coefficient $^{\mathrm{a}}$} & \multicolumn{4}{|c|}{ Percentage of Industries } \\
\hline Goods Type & Industries & Growth & Level & Pos \& Sig & Neg \& Sig & Pos \& Insig & Neg \& Insig \\
\hline Organized Exchange & 89 & -0.262 & -1.309 & 0 & 47 & 39 & 64 \\
\hline Reference Priced & 125 & -0.158 & -1.472 & 0 & 29 & 16 & 46 \\
\hline Differentiated & 237 & -0.089 & -1.349 & 3 & 23 & 22 & 45 \\
\hline Total & 451 & -0.142 & -1.388 & 2 & 28 & 22 & 48 \\
\hline
\end{tabular}

*Significant at the $95 \%$ level

a : Weighted distance coefficent. 